"This is the peer reviewed version of the following article: Vijeyarasa, R. (2018), A move in the Right Direction? The Model Law against Trafficking in Persons and the ILO Operational Indicators. Int Migr, which has been published in final form at https://doi.org/10.1111/imig.12504. This article may be used for noncommercial purposes in accordance with Wiley Terms and Conditions for Self-Archiving." 


\section{A move in the right direction? The Model Law against Trafficking in Persons and the ILO Operational Indicators}

\section{INTRODUCTION}

Despite high levels of interest from a multi-disciplinary audience of academics, governments, non-governmental organisations (NGOs) and other stakeholders, the global response to human trafficking continues to be plagued by definitional problems. This is not in spite of, but primarily because of, the enactment of the UN Protocol to Prevent, Suppress and Punish Trafficking in Persons, Especially Women and Children, supplementing the UN Convention against Transnational Organised Crime (United Nations Trafficking Protocol 2000). To its credit, the enactment of the Trafficking Protocol in 2000 sought to offer the global community the first-ever definition of trafficking and the parameters for who constitutes a victim. What resulted, however, was an inaccurate, ill-defined and cumbersome definition that fails to accord with the realities of human trafficking.

An extensive body of academic work has been dedicated to outlining the shortcomings of the Trafficking Protocol. Among the most significant problems, the international instrument offers only weak accountability mechanisms and loose oversight of its implementation (Gallagher 2015); lacks a human rights based approach to trafficking, in practice, characterizing human rights as an add-on to the Trafficking Protocol; and through its implementation, has exacerbated oppressive measures against sex workers and migrants in the name of combating trafficking (Wijers 2015, 56). A number of authors, including myself, have critiqued the failure of the Trafficking Protocol to provide explicit clarity on the relationship between prostitution/sex work and trafficking (Vijeyarasa, 2015; Ditmore 1998, 43). In brief, while the Trafficking Protocol served to clarify a phenomenon that for too long was left undefined and unregulated (Gallagher 2015, 16) and outlined obligations that we now, admittedly, take for granted, namely criminalising trafficking and protecting victims (Gallagher 2015, 16), it unfortunately comes up short as the first and most dominant global instrument aimed at tackling the problem.

These limitations in the definition of trafficking offered by the Trafficking Protocol have had significant implications. One of the most obvious from a public policy perspective is its emphasis on the use of coercive or forced practices at the point of origin rather than the more realistic scenario of deception, fraud and exploitation at the destination. This is despite growing evidence of victims' initial free consent and the reality that, while a decision may have at one 
point been a free and conscious one, the migrant nonetheless ends up an exploited victim. As will be demonstrated below, it is on this question of autonomous or voluntary consent and the erroneous emphasis on such concerns as abduction, deception or coercion at the point of origin, that the Trafficking Protocol has proved most problematic. What has resulted is a tendency to erase from the law those individuals who falls outside the narrowly constructed category of victim.

Partly in response, since 2000, several related international instruments have been drafted, two of which are the subject of my analysis in this article. They have been chosen because of their global nature and in light of the extent to which they have helped to correct many of the shortcomings we originally witnessed in the Trafficking Protocol.

First, the United Nations Office on Drugs and Crime Model Law against Trafficking in Persons (UNODC 2009a) is a tool developed to encourage states to become signatories to the Convention against Transnational Organised Crime and to assist States to make amendments to their domestic laws to meet the requirements of the Trafficking Protocol. Second, the International Labour Office's Operational Indicators on Trafficking in Human Beings, published in 2009, provide practitioners four sets of operational indicators based on expertise from twenty-seven European Members States. While neither is a binding legal instrument, both act as soft law that have aided in alleviating some of the most egregious problems with how trafficking was framed in 2000.

Several other instruments of international law and policy have made a significant contribution to how we understand trafficking and interpret the principles of the Trafficking Protocol. This includes the UN Recommended Principles and Guidelines on Human Rights and Human Trafficking; the 2005 Council of Europe Convention on Action against Trafficking in Human Beings; and the 2011 European Union Directive on Preventing and Combating Trafficking in Human Beings and Protecting its Victims. ${ }^{1}$ Among the array of instruments that now exist, I have chosen to focus in this article on the Model Law and the ILO Operational Indicators in light of the general absence of significant literature on either of these soft law instruments, particularly compared to the voluminous literature analyzing binding law in this area. Moreover, both the Model Law and ILO Indicators have proved their considerable worth in advancing both debates and practice when it comes to human trafficking, particularly at the global level.

In order to analyse the legal instruments discussed in this paper, I offer readers several hypotheticals that reflect different levels of autonomy exercised by victims in the process of "being trafficked" using both real and hypothetical cases. ${ }^{2}$ First, I present Chamoli, who is sold 
by her lover, as the "coerced victim of trafficking". By virtue of being 16 years of age, and therefore a child by definition in international law, Chamoli is a victim of trafficking under Article 3 of the Trafficking Protocol. Despite the way in which Chamoli neatly fits the Trafficking Protocol, evidence from the field demonstrates that cases like Chamoli's are rare occurrences and represent a very small proportion of trafficking cases.

Next I present two examples of non-coerced victims. First, we have Hoàng, from Vietnam, who chooses to work abroad due to the limited opportunities for work at home and given the weight of the expectations she bears to contribute to her family's income. Next, the autonomous victim of trafficking is represented by Patience, a Ghanaian migrant who sees excitement and opportunity in Italy, but who is falsely led to expect certain conditions of work abroad that fail to come to fruition. ${ }^{3}$

Chamoli, Hoàng and Patience illustrate three contrasting experiences pertaining to the movement of victims and their experiences of work. By undertaking this comparative analysis of the autonomy of these three victims, I explore the appropriateness of the law when it comes to criminalising trafficking. Having spent time in the field collecting data from Ghana, Vietnam and Ukraine, I use this experience and first-hand data to espouse that the "autonomous victim", "Patience", is a more accurate portrayal of a typical victim of trafficking. In turn, I explain why Chamoli is not the norm.

As I will show, a narrow and biased understanding of trafficking shifts our attention to the non-autonomous victim, often excluding individuals like "Patience," the victim-agent, leaving them vulnerable to further abuse in a law-enforcement environment. The Model Law and Operational Indicators have helped to address these shortcomings. This is both in terms of establishing more realistic standards, fitting to address the cases of Hoàng and Patience, but also due to the tendency of these newer instruments to emphasise coercion, deception and abuse of vulnerability at the point of destination.

Adopting a feminist legal perspective, my purpose in developing these hypotheticals is to examine the limitations of the Trafficking Protocol in accommodating the autonomy exercised by victims of trafficking in the process of migrating into exploitative conditions of work. In particular, I seek to demonstrate that international law's treatment of the issue of trafficking fails to protect (i.e. define as victims and offer legal redress) the victims whose experiences form some of the most common cases of exploitative movement that are taking place on the ground. My principle argument is that autonomy is in fact very evident in cases of trafficking. It is a central feature in migratory movement: autonomous decisions of willing migrants to seek work and betterment abroad. Failure to recognise this results in an inaccurate portrayal of 
victims' knowledge, willingness, their expectations of work and life abroad and their right to legal redress. In this article, therefore, I seek to identify the strengths in international law when it comes to trafficking, the problems that remain and potential solutions, particularly through the use of soft law, as to how international law can better reflect trafficking and victimhood.

Before moving on, two important notes on 'autonomy' are required. First, feminist legal theory on the topics of trafficking and sex work - a relevant and somewhat related body of literature - frequently uses the concepts of agency and autonomy interchangeably. I favour the term autonomy over agency, speaking of the victim-agent as an individual whose life choices either do or do not demonstrate autonomous decision-making. Second, there is already an existing bias within discourses on agency and autonomy towards women. ${ }^{4}$ Why do we question the levels of autonomy exercised by women in decision-making and not the autonomy of all victims in the process of moving? I contend that the primary reason has been the dominance in these debates of feminist theorists and their focus on the topic of sex work/prostitution and not simply autonomy but sexual and bodily autonomy. Throughout this article, I have made a deliberate attempt to provide examples pertaining to all forms of labour and to both trafficking for sexual and labour exploitation.

\section{INTERNATIONAL LAW AND THE DEFINITION OF VICTIMHOOD}

Before going to the heart of this discussion on the law's treatment of the autonomy exercised by victims of trafficking, it is important to provide some contextual analysis of the three international instruments that are the subject of this article.

\section{The UN Trafficking Protocol}

While the international community long ago came to an agreement that human trafficking is an egregious violation of human rights (International Agreement for the Suppression of the White Slave Traffic 1904), it is arguable that a consensus on the meaning of the term trafficking was not reached until 2000. In this respect, the enactment of the Trafficking Protocol was unquestionably a pivotal moment in the evolution of a global response to human trafficking. Prior to this, various legal instruments (particularly ILO conventions) and resolutions existed to govern the issues of forced and child labour, slavery and practices similar to slavery, including white slavery and commercial sexual exploitation of children and adults (e.g. International Convention for the Suppression of the White Slave Traffic 1910; ILO Convention Concerning Forced and Compulsory Labour 1930; ILO Convention Concerning Minimum Age 
for Admission to Employment 1973). In those instruments, the terms "traffic" or "trafficking", although occasionally mentioned, were never defined.

In 2000, many in the global community gathered in Palermo, Italy, to discuss and debate growing confusion within this field. Clarity was needed on the overlaps and distinctions between prostitution and trafficking and between trafficking and migrant smuggling, as well as on the relative weight to be accorded to crimes of a sexual and non-sexual nature. This moment was preceded by a resolution introduced by the United States of America at the April 1998 session of the UN Commission for Crime Prevention and Criminal Justice, calling for the development of a protocol on trafficking in women and children under a proposed UN Convention against Transnational Organised Crime. The draft protocol itself was introduced by the United States and Argentina at the first negotiation session for the Convention in January 1999.

In the lead-up to Palermo, NGOs lobbied member states on the draft language of the protocol. Abolitionist feminists and pro-sex work feminists were unsurprisingly divided. ${ }^{5}$ The UN, particularly the UNODC, was at the centre of discussions in Palermo, along with the International Organisation for Migration (IOM). The outcome of these discussions was the UN Protocol to Prevent, Suppress and Punish Trafficking in Persons. The Trafficking Protocol defines trafficking as:

... the recruitment, transportation, transfer, harbouring or receipt of persons, by means of the threat or use of force or other forms of coercion, of abduction, of fraud, of deception, of the abuse of power or of a position of vulnerability or of the giving or receiving of payments or benefits to achieve the consent of a person having control over another person, for the purpose of exploitation. Exploitation shall include, at a minimum, the exploitation of the prostitution of others or other forms of sexual exploitation, forced labour or services, slavery or practices similar to slavery, servitude or the removal of organs; ... (3(a), Trafficking Protocol)

The Trafficking Protocol's definition revolves around three separate elements: first, the action ("recruitment, transportation, transfer, harbouring or receipt of persons"); second, the means; and finally, the purpose of exploitation. For a given situation to be deemed one of trafficking, all three elements (action, means and purpose) must be present, with the exception of cases involving children (those under 18 years of age). In these instances, no means need to be identified (Article 3(a)). That is, the movement of any persons under the age of eighteen for the purpose of exploitation is defined as a case of trafficking, regardless of the presence of any consent. 
Unsurprisingly given its annexation to a convention focused on organised crime, the Trafficking Protocol adopts a criminal justice perspective towards the prosecution of the alleged trafficker. It therefore focuses on both the actions of the trafficker(s) (actus rea) and their mental intent, or the purpose of the crime (mens rea). After its enactment, this criminallaw oriented definition found its way, in various forms, into national legislation and policy instruments and is cited in most, if not all, literature as the definition of human trafficking.

\section{The UN Office on Drugs and Crime's Model Law against Trafficking in Persons}

The UNODC Model Law was the outcome of a project aimed at addressing some of the above concerns with the Trafficking Protocol. It emphasises adaptability, the needs of individual States and the importance of drafting anti-trafficking provisions that accord with local context and that complement and not contradict domestic law. At the same time, alongside the optional provisions, there are mandatory ones: these are integral to the operation of the Model Law, even if they are "not mandated by the Protocol per se" (UNODC 2009b, 1).

The Model Law deals extensively with all provisions of the Trafficking Protocol. For the sake of this discussion, I deal with the most pertinent suggestions from the Model Law. Particularly noteworthy, the Model Law makes a significant departure from the Trafficking Protocol by expanding its applicability: "This Law shall apply to all forms of trafficking in persons, whether national or transnational and whether or not connected with organized crime" (UNODC 2009b, 8). As a point of interest, the Model Law contains a much more expansive discussion on the application of measures in a non-discriminatory fashion, naming grounds of non-discrimination, such as sexual orientation, that are not explicitly recognised in international law.

The Trafficking Protocol does not provide any guidance regarding a key element of its definition of trafficking: the "abuse of power or a position of vulnerability". 6 The Model Law assists in this respect, offering several alternatives for wording that emphasise a person succumbing because they believe they have "no real and acceptable alternative but to submit" (UNODC 2009b, 9) or taking advantage of "the vulnerable position a person is placed in" based on a number of factors, including illegal entry into a country, or the lack of proper documentation or addiction to the use of any substance. Oddly, "pregnancy" is named as a vulnerability factor (UNODC 2009b, 9). I have been unable to find any empirical study demonstrating that pregnant women experience a greater likelihood of being trafficked.

The Model Law contains two potential definitions of the term "coercion", emphasising both physical and psychological harm. It also offers a definition of deception, which as I will 
demonstrate below, is a central concept in relation to trafficking - and one that, to a certain but limited extent could overlap with coercion (Vijeyarasa 2015, 75).

Finally, the Model Law addresses the much-debated issue of sex work and its relationship to trafficking. It explicitly states, "[ $\mathrm{t}]$ he Protocol addresses the exploitation of prostitution only in the context of trafficking" and that " $[\mathrm{t}]$ here is no obligation under the Protocol to criminalize prostitution" (UNODC 2009b, 13). Importantly the Model Law makes explicit that a particular situation in which a victim may have consented can still constitute trafficking, a scenario often reflected in qualitative studies of trafficking (see for example Vijeyarasa 2015):

...It also means, for example, that a person's awareness of being employed in the sex industry or in prostitution does not exclude such person from becoming a victim of trafficking. While being aware of the nature of the work, the person may have been misled as to the conditions of work, which have turned out to be exploitive or coercive (UNODC 2009b, 26).

Beyond these select points, the Model Law offers suggested drafting for how to incorporate all aspects of the Trafficking Protocol into domestic law.

\section{The International Labour Office's Operational Indicators on Trafficking in Human Beings}

Commonly known as the ILO Operational Indicators on Trafficking in Human Beings (henceforth ILO Operational Indicators), this set of indicators actually emerged from joint efforts with the European Commission. These indicators were developed using the Delphi Method, one that reaches a consensus based on input from a wide range of experts (from each of the then 27 EU Member States), including police, government, academia and research institutes, NGOs, international organisations, labour inspectorates, trade unions and judiciaries.

Before outlining the contribution that the ILO Operational Indicators have made, I begin with their most obvious shortcoming. The Indicators are a collection of four different sets of indicators: (a) Trafficking of adults for labour exploitation; (b) Trafficking of adults for sexual exploitation; (c) Trafficking of children for labour exploitation; and (d) Trafficking of children for sexual exploitation. Herein lies the problem: the indicators once again affirm a false and unnecessary divide between labour and sexual exploitation, risking gravitation towards the sexual and salacious and gender stereotypical notions of the protection of women.

For the purposes of this discussion, I will focus on those indicators related to adult victims but the critiques as well as the praise offered in this article in many instances equally apply to the child-focused indicators. The ILO states that someone is a victim of trafficking if:

- two strong indicators apply; 
- one strong indicator and one medium or weak indicator applies;

- three medium indicators apply; or

- two medium indicators and one weak indicator apply.

This ability to combine indicators with different levels of gravity allows us to identify a wide variety of scenarios that fall within the ambit of trafficking. The ILO Operational indicators prove useful for the recognition of country-specific circumstances, where certain factors may be more present in one country than in another, where they may in fact not be a feature at all. For instance, in the Emirates and Saudi Arabia, confiscation of the passports of domestic workers, in cooperation with the authorities, is more commonly practiced (Vlieger 2012, 190), but may not be a common practice in other regions.

Undoubtedly as a result of the Trafficking Protocol, certain indicators continue to focus on the atypical aspects of human trafficking. This is particularly in relation to coercive recruitment for both sexual and labour exploitation. Indicators that include, for instance, abduction, forced marriage, selling of victims, isolation and confinement continue to promote a skewed picture of trafficking as a coerced and non-autonomous decision and shift attention away from exploitation at the destination. Several indicators related to coercion at the destination also promote particular assumptions about the experience of being trafficked, such as confiscation of documents, isolation and confinement. These may prove problematic if such elements are used as criteria for victimhood, without exception. For instance, an analysis of a (limited) body of Australian trafficking-related case law suggests that victims often have free movement, rarely have their documents taken away and even have access to mobile phones (Schloenhardt and Bowcock 2015, 600).

To their credit, deception is given significant weight among the ILO indicators, with particular attention given to deceit about the nature of the job, location or employer. Other points of deception provided include the conditions of work, content or legality of the work contract, deception about family reunification, housing and living conditions, the legality of documentation, or the ability to obtain legal migration status, travel and recruitment conditions, wages and earnings, or promises of marriage or adoption.

Similarly, the indicators show a very accurate picture of exploitation, incorporating indicators on exploitation through bad living conditions, excessive working days or hours, hazardous work, low or no salary, no respect for labour laws or contracts, no social protection, bad working conditions and wage manipulation. Such a picture of exploitation is reflected in numerous studies of human trafficking (Busza, Castle, and Diarra 2004, 1370; Agustín 2009, 
98; Vocks and Nijboer 2000). Interestingly, "coercion at the destination" is given its own category - although in reality this is closely intertwined with indicators related to exploitative conditions of work - including forced tasks or forced clients and being forced to perform illicit or criminal activities.

A more complicated picture relates to abuse of a position of vulnerability. Limited research exists on the pre-departure demographic of victims, with particular characteristics frequently presumed to relate to trafficking without substantiation (Vijeyarasa 2015, 8-9). For example, increasingly research is debunking the myth that victims are poor and lack education (Vijeyarasa 2015, chaps. 5-6). In an effort to be more accurate and specific, the ILO Operational Indicators name lack of language as the specific education-related vulnerability abused at the recruitment stage. False information about a range of matters is also incorporated, including lack of information generally as well as specifically about the law, attitudes of authorities and successful migration.

Abuse of a "difficult family situation" is also named. On this point, I would raise significant doubts. On the one hand, social control theory places emphasis on the role of the family in providing attachment and a social network, suggesting strong family relationships reduce vulnerability to being trafficked (Vijeyarasa 2015, 71; Vocks and Nijboer 2000, 381). However, the phrase "difficult family situation" contains vague language; evidence of a sound relationship between, for example, domestic violence and trafficking is at best weak (Vijeyarasa 2015, 94). We can conclude that while the ILO Operational Indicators have advanced our practical conception of what constitutes human trafficking, flaws remain. In the following section, I delve further into each of these three legal instruments through the use of hypotheticals.

\section{COERCION, AUTONOMY AND THE MIGRANT WORKER: INTERNATIONAL LAW'S FRAMING OF THE TRAFFICKING VICTIM}

Conceptions of trafficking have evolved substantially since the enactment of the Trafficking Protocol. For many years, trafficking was widely believed to entail the kidnapping, abduction and selling of women (Hughes and Denisova 2001; Human Trafficking 2005; Moodysson 2003; Kara 2010; Skinner 2009; Androff 2011; Balos 2004). However, the degree to which we have seen change is debatable. Despite some authoritative voices claiming that the notion that trafficking is "concerned solely with the cross-border sexual exploitation of women and children has lost all authority" (Gallagher 2015, 16), many authors, including myself, disagree (Vijeyarasa, 2015; Wijers 2015, 56; Schloenhardt and Bowcock 2015). 
This section aims to develop an understanding of what role is played by the international legal framework in reinforcing these misconceptions or in challenging them. Do we continue to gravitate around the 2000 definition or has our understanding of trafficking and who are the victims sharpened as a result of new legal and policy instruments?

\section{The coerced victim of trafficking and international law}

I begin with the case of Chamoli, documented by the then UN Special Rapporteur on Violence against women, its causes and consequences, Radhika Coomaraswamy during a 2001 visit to Nepal (also cited in Balos 2004 in an article critiquing the use of victims' consent in a trafficker's defence ${ }^{7}$ ). I present Chamoli as an example of the coerced victim of trafficking:

...[Chamoli] was 16, she met a young man and fell in love with him. He promised to marry her but insisted that she come away with him to India. So one day she ran away with the boyfriend... Once they reached Poona, Chamoli was taken to a house where there was an older Nepali lady and many young girls. The lady gave her boyfriend some money and then he told her that he was going for a moment. He never came back. Chamoli suddenly realized she had been sold into prostitution. She refused to accept her new trade. She was repeatedly beaten. She was not given any food. When she screamed in defiance, knives and chilli powder were held to her genital area. Finally exhausted and worn down, she agreed to provide sexual services. After a few weeks, she was sold to a large brothel in Bombay. She served about 10 clients every night of the week (Coomaraswamy 2001, II 12).

While the example of Chamoli is not necessarily a case of abduction from start to finish, what is key in Chamoli's narrative is that her decision to elope with her boyfriend cannot be equated to a conscious and willing acceptance of her final situation. That is, Chamoli intended to elope and live with her boyfriend in India. She did not seek work in India, nor did she have expectations or false hopes regarding potential work abroad. While her original decision to flee with her boyfriend might be considered a form of autonomous decision-making, she is coerced in the sense that, having been sold against her will, at no point did her intention at the outset regarding work in India relate in any way to what ended up being her sexual exploitation in a brothel in India.

Chamoli's story is a classic case under the Trafficking Protocol (and is therefore naturally also captured by the Model Law and ILO Operational Indicators which stem from the Protocol). She is transferred and harboured by fraud and deception, her vulnerability is clear and her 
experience of exploitation is perfectly encapsulated in Article 3 of the Trafficking Protocol. Moreover, if there is any doubt as to her status as a victim due to her initial decision to voluntarily leave Nepal, she is only 16 years of age; as a child, her consent is deemed irrelevant.

While a "classic" case under the Trafficking Protocol, Chamoli's story is atypical and epitomises the deeply engrained slavery-like imagery that the Trafficking Protocol fostered when it was enacted. Problematically, such stories are reiterated, somewhat carelessly, in the literature. Siddharth Kara tells readers of fellow Nepalese girl Maya who was sold by her parents to a local agent for USD 55, ostensibly to work in a carpet factory. Maya, who Kara explains was forced to work in a brothel in Mumbai's "red light district", is described by Kara as "emblematic of the hundreds and thousands of women and children trafficked and forced into prostitution each year" (Kara 2010,3). Despite criticisms that his literature is a "set of speculations" (Cheng 2010, 364) that "relies on salacious material and hero fantasies", Kara's work is praised by The Financial Times as "an eloquent, campaigning book that addresses an evil that belittles our humanity" (Birchall 2009).

\section{The partially autonomous victim of trafficking and international law}

Next I turn to the "partially autonomous" victim. This example attempts to give recognition to the decision-making power of the individual migrant and seeks to honour the individual's stated preferences. However, the level of autonomy seemingly exercised by the individual is diminished by other socio-economic inequalities that have impacted their decision-making:

Hoàng is a 19-year old Vietnamese woman from An Giang in Vietnam. Her father is ill and her mother sells food, toothpaste, toilet paper from a small shop at the back of their house. Hoàng has 4 younger siblings and an older brother, who lives and works in Ho Chi Minh City. Her mother struggles to cover the costs of books, uniforms and transport to keep her younger siblings in school. Hoàng decides to find work in Cambodia. She has heard that there are opportunities to work in bars as a waitress. She also knows that some women end up working as sex workers in Phnom Penh in Svay Pak and Tuol Kork. Hoàng solicits the help of a friend of a friend, who travels regularly to Cambodia and who explains to her that there are plenty of opportunities for work in Svay Pak and some girls earn as much as USD500/month, significantly higher than the average monthly salary in Vietnam. Together with this acquaintance, Hoàng travels to Svay Pak with the hope of finding work at a Karaoke Bar. When she arrives at the Karaoke Bar, her acquaintance introduces her to the owner, who offers her only USD10/day for a 10-hour working day as a waitress in the bar, significantly less than 
Hoàng expected. Her acquaintance insists that she pay her a portion of her income for having found her work. When Hoàng refuses, the acquaintance threatens to inform her family and friends in An Giang that she has become a sex worker in Cambodia (whether true or not). Fearing shame on her family, Hoàng agrees to give the acquaintance 10 per cent of her earnings.

This narrative is based, in part, on the fairly extensive empirical research about Vietnamese victims of trafficking and Vietnamese sex workers abroad. This includes testimonies concerning unmet expectations of trafficked women, particularly related to forced sex work and work under a system of debt. Research also reports a complex decision-making process that takes into consideration family expectations, financial incentives and personal ambition (Busza 2004, 244; Busza, Castle, and Diarra 2004, 1370). Mirroring the partial autonomy shown by the Hoàng archetype, Busza further notes, "Some women did not want to enter sex work but felt it was a familial responsibility given the lack of other options to earn money; others voluntarily migrated to Cambodia for different work but then moved to brothels when other options proved difficult. Finally, a few women reported being 'tricked' into sex work and subsequently forced into debt. These women's experiences of deception and fraud clearly represent 'trafficking' and intended exploitation” (Busza 2004, 245).

In the case of Hoàng, while she clearly exercised a decision to seek work in Cambodia, she had a range of options regarding whether or not to leave Vietnam, and she was largely aware of the nature of the work she would do as a waitress in Cambodia, her freedom of choice is diminished in this narrative. I deem her decisions partially autonomous because they are affected by factors that include both familial obligations and weaker socio-economic circumstances.

It is arguable - and some authorities might argue as such - that Hoàng is not a victim of trafficking. Her status hinges largely on how the phrase "abuse of power or position of vulnerability" in the Trafficking Protocol is understood. It is here that we see the real value of the Model Law. Does Hoàng feel she has "no reasonable alternative but to submit to the labour or services" (UNODC 2009b, 10) being demanded of her? No reasonable alternative is a high standard, one that Hoàng probably does not meet. However, her acquaintance takes advantage of her illegal status in Cambodia. Moreover, she is threatened. The term "threat" appears only once in the Trafficking Protocol in Article 3. The Model Law helpfully describes "forced labour or services" as "all work or service that is exacted from any person under the threat of any penalty and for which the person concerned has not offered him- or herself voluntarily" 
(UNODC 2009b, 14). Threats to expose Hoàng's work to her family may meet this requirement.

Turning to the ILO Operational Indicators, and the indicators focused on trafficking of adults for labour exploitation, Hoàng is in fact very knowledgeable and is unlikely to meet the requirements for deceptive recruitment, coercive recruitment or recruitment by abuse of vulnerability. Much of her exploitation occurs at the destination point after she has voluntarily travelled to Cambodia - a scenario that, based on my past research, I believe to be more typical of trafficking cases. In this case, three medium indicators are evident: she faces a low salary, with no respect for labour laws and no social protection. In addition, she faces a dependency on her exploiter, is living in an unknown area and has an economically-weak family situation, again meeting the requirement of three medium-level indicators for abuse of vulnerability at the destination. Hoàng's case proves well the value-add of the Model Law and ILO Operational Indicators.

Turning now to another hypothetical example of partially autonomous victimhood, here I move beyond the often typical portrayal of victims of trafficking as single, young women entering sex work. This example helps to further clarify the test for partially autonomous decision-making.

Đặng and Bùi are a Vietnamese couple from Bắc Giang Province in Red River Delta in Vietnam with 2 children. Together they live with Đặng's mother and father in an agrarian community. They are both farmers, growing rice on land owned by the government but allocated to them for cultivation. Đặng has a brother who received a scholarship to study in Russia and later moved to Western Europe and found a job. He has heard that the work opportunities are acceptable. Both Đặng and Bùi decide to try to find work in Europe for a few months, with the hope of maybe later sending over their children and staying in Europe permanently or returning to Vietnam with a bit more money for their family. They have a Vietnamese friend who, with the help of a friend in neighbouring China, managed to leave Vietnam and find work in Spain. Their Vietnamese friend puts them in touch with the Chinese acquaintance. After considerable negotiations and many months, the Chinese acquaintance arranges their passage and work in a factory in Spain. They are told that they will work between 8-10 hour days, 5-6 days a week and are reassured that it is easy to find accommodation with other Vietnamese living in Spain. Although they expected to pay for their own passage and an additional fee of USD 3,000 to the Chinese contactor, upon arrival in Spain, a debt of USD30,000 is imposed on the couple instead. Further, upon arriving at the factory, they discover that they have no 
choice but to sleep on a dirty mattress in the factory, where they must also eat and use the toilet. They also discover that they must work 18 to 20 hour days, with no days off. They have no idea how long it will take them to pay off their debt or whether they can escape. They worry about their children whom they have left behind and question how their elderly parents will be able to care for them in their absence. ${ }^{8}$

Both Đặng and Bùi are a partially autonomous trafficked couple, whose decision-making is limited by their political and socio-economic context. While their story differs from Hoàng in many significant ways, there are numerous and important parallels when it comes to elucidating the meaning of "autonomy". Clearly their lives and livelihoods in Vietnam are constrained by their social and political context, including Vietnam's (newly-emerging) middle-income status, the Communist system in which they are unable to own land in their own right, and the limited income available from the agrarian economy. Perhaps too their capacity for autonomous decision-making is also weak, the couple relying heavily on the path taken by Đặng’s brother. They are also limited by their obligations concerning the care of their children but also their responsibilities towards Đặng’s mother and father.

Under the Trafficking Protocol, Đặng and Bùi are recruited and travel to Spain under deceptive conditions. Abduction and coercion are irrelevant. The word debt or phrase 'debt bondage' was not explicitly included in the Trafficking Protocol. This is a stark omission that has not received the severe criticism it deserves. ${ }^{9}$ In contrast, the Model Law offers several alternative definitions of "debt bondage", including one that draws from the Supplementary Convention on the Abolition of Slavery, the Slave Trade, and Institutions and Practices Similar to Slavery, Article 1:

(a) Debt bondage, that is to say, the status or condition arising from a pledge by a debtor of his personal services or of those of a person under his control as security for a debt, if the value of those services as reasonably assessed is not applied towards the liquidation of the debt or the length and nature of those services are not respectively limited and defined (Supplementary Convention on the Abolition of Slavery, the Slave Trade, and Institutions and Practices Similar to Slavery 1957; see also Vijeyarasa and Bello y Villarino 2013 for more on the Slavery Convention).

Again, the detailed elucidation of the notion of abuse of vulnerability in the Model Law and ILO Operational Indicators prove particularly helpful. Specifically with respect to the latter, Đặng and Bùi have suffered deceptive recruitment (three medium indicators present - deceived 
as to conditions of work, housing and living conditions, wages and earnings and possibly also about family reunification); recruitment by abuse of vulnerability (at least three medium indicators present - vulnerability related to a difficult family situation, economic reasons, false information about successful migration, their family and personal situations); exploitation at the destination (strong indicators of excessive working days and hours, as well as numerous medium indicators - bad living conditions, no respect for labour laws, no social protection and very bad working conditions); and arguably coercion at the destination (two strong indicators - debt bondage and isolation in an unknown country where they probably do not speak the language). The experience of Đặng and Bùi is therefore well reflected by the ILO Operational Indicators.

\section{The autonomous victim of trafficking and international law}

Finally, I turn to the trafficked agent whom I deem to be an "autonomous victim", having voluntarily entered into what unexpectedly ends in trafficking-like conditions:

Patience, from Takoradi, Ghana, is introduced to smuggler " $A$ ” by a good friend, who vouches for his reliability. " A" offers to organise Patience's passage to Milan, Italy and her work upon arrival for USD10,000. Patience decides to accept A's offer, as does her friend, as it sounds like a fun opportunity and a good way to earn some money. Patience knows she will be working as a sex worker in a brothel, and expects to work 6 days/week from around 9pm to 4am, for which she will earn around USD2,000 per month. Before leaving Ghana, Patience pays " $A$ " USD4000, as a deposit for his help. Having arrived in Milan, as planned, Patience begins works in A's brothel. However, during her first week of work, Patience is told that "A will keep 50 per cent of her earnings. As a result, she earns only USD 1,000 per month, all of which she must give to " $A$ " in order to pay off her debt. During her first month of work, " $A$ " insists that she works 7 days/week, claiming that she is not seeing enough clients. Occasionally Patience's clients become abusive but she is offered no protection from the brothel. On more than one occasion, she is forced to have sex with without a condom and is unable to deny the insistent demands of clients, with "A" refusing to turn away abusive clients. She sleeps in a near-by share house, with several other women who also work at the brothel. The house is guarded by a security guard who is paid by " $A$ " and prevents any of the women from leaving the house at night. After 3 months of working at the brothel, she is tired, frequently ill, and still owes " $A$ ", USD3,000 before she can begin to earn an income of her own. 
Patience is the "autonomous trafficked agent-victim". The example moves away from the paradigmatic image of the young and naïve innocent girl lured by evil traffickers that is often criticised in the academic literature by pro-sex worker feminists (Doezema 1999). Patience chose to earn money as a sex worker and was aware that she would be working in the Italian sex industry before leaving Ghana, as is said to be frequently the case with undocumented migrant women sex workers in Europe (Agustín 2005, 101-2; Busza 2004, 244). While her autonomy is clear in her initial decision, her situation changed from being a migrant sex worker to a migrant victim of trafficking when her negotiated expectations of work in Italy do not come to fruition, ranging from her rate of pay, the debt imposed on her as well as her living conditions. These are the "unmet expectations" that are frequently central to the experience of human trafficking; Patience is a "voluntary victim" of trafficking (Vijeyarasa 2010).

Patience is unsuccessful in her migratory pursuits. Yet, her voluntary decision-making and knowledge places her outside of the scope of many domestic trafficking laws. To the contrary, she is likely to be viewed by the law as smuggled migrant. Again, the absence of references to debt bondage in the Trafficking Protocol severely undermines her legal rights.

The Model Law, however, offers her greater protection by escaping the difficult language of "the recruitment, transportation, transfer, harbouring or receipt of persons". Patience is deceived and exploited at the destination point and her vulnerability has been abused. Her vulnerability arises from her precarious status, having entered and stayed in Italy illegally (UNODC 2009b, 10). Her case is one of debt bondage and as per the earlier discussion of Đặng and Bùi, meets the definitional requirements of debt bondage as set out in the Model Law.

Concerning the ILO's Operational Indicators, her experience of trafficking was at the destination point. She is a victim of exploitation (meeting several medium indicators hazardous work, no salary, lack of respect for labour laws, no social protection and very bad working conditions); she has suffered coercion at the destination (several strong indicators including debt bondage, forced clients, confinement and surveillance and potentially several medium indicators, including the threat of even worse working conditions); and has suffered abuse of vulnerability at the destination (including three medium indicators - the difficulty of living in an unknown area, her illegal status and precarious relationship with authorities and arguably her dependence on her exploiters). From this example, we can see how voluntariness can be used to exclude a victim from the law's protection, despite evident violations of their rights; the Protocol's failure to recognize nuance and the realities behind the practice of trafficking marginalizes victims to the point of pushing them beyond the law's protection. 


\section{CONCLUDING REMARKS}

This article demonstrates the shortcomings of the Trafficking Protocol - which are well documented, albeit not as well examined in terms of concrete hypotheticals that depict realworld scenarios of trafficking as has been attempted in this article. Three different framings of the agency exercised in the trafficking process are offered above: first, Chamoli, who is sold by her lover, representing the kidnapped, abducted victim; secondly, Hoàng and the couple, who choose to work abroad due to limited opportunities for work at home and given the weight of familial obligations, and Patience, who sees excitement and opportunity in Italy, but is falsely led to expect certain conditions of work abroad that fail to come to fruition.

I have articulated these three approaches to "autonomy" for two reasons. The cases of Chamoli, Hoàng (and Đặng and Bùi) and Patience allow us to view the different levels of autonomy involved in the decision-making that exists behind many experiences of trafficking. Much greater autonomy exists than is often conceded. Second, these cases illustrate the oftencriticised problems with how trafficking and its victims are framed in the Trafficking Protocol. In response, both the Model Law and the ILO Operational Indicators have substantially advanced our theoretical, legal and practical response to the issue of trafficking.

At the time of its enactment, the Trafficking Protocol situated trafficking within the realm of criminal justice, largely unapologetically. At that time, States' primary interests were in ending trafficking as a form of transnational organised crime. The rights of victims to redress were explicitly brought into the discussion but were never the core focus of the issue. A multiplicity of experiences that are actually involved in trafficking-related exploitation was therefore largely unrepresented.

This article highlights the importance of recognising such a spectrum of migratory experiences, with differing degrees of autonomy, consent, deception and exploitation. Wherever an individual is placed on the migration spectrum, common experiences include arduous journeys, low wages, hazardous working environments and unsanitary living (Vijeyarasa 2015, 180). Chamoli, Hoàng, Đặng and Bùi and Patience all sit at different points of the spectrum and yet the law - depending on how it is drafted - may preclude victims who parallel these examples from being identified as a victim and receiving redress. To be simultaneously a victim and an agent of one's destiny should not be impossible under the law.

\section{References}


Agustín, Laura. 2005. "Migrants in the Mistress's House: Other Voices in the 'Trafficking' Debate." Social Politics: International Studies in Gender, State \& Society 12 (1): 96117. https://doi.org/10.1093/sp/jxi003.

. 2009. "TIP: Trafficking in Persons, the No-Methodology Report." The Naked Anthropologist (blog). June 26, 2009. https://www.lauraagustin.com/tip-traffickingin-persons-the-no-methodology-report.

Androff, David K. 2011. "The Problem of Contemporary Slavery: An International Human Rights Challenge for Social Work." International Social Work 54 (2): 209-22. https://doi.org/10.1177/0020872810368395.

Balos, Beverly. 2004. "The Wrong Way to Equality: Privileging Consent in the Trafficking of Women for Sexual Exploitation.” Harv. Women's L.J., January. http://scholarship.law.umn.edu/faculty_articles/127.

Birchall, Jonathan. 2009. "Sex Trafficking.” Financial Times, January 24, 2009. https://www.ft.com/content/339b0ee8-e8db-11dd-a4d0-0000779fd2ac.

Busza, Joanna. 2004. "Sex Work and Migration: The Dangers of Oversimplification: A Case Study of Vietnamese Women in Cambodia." Health and Human Rights 7 (2): 231-49. https://doi.org/10.2307/4065357.

Busza, Joanna, Sarah Castle, and Aisse Diarra. 2004. "Trafficking and Health.” BMJ 328 (7452): 1369-71. https://doi.org/10.1136/bmj.328.7452.1369.

Cheng, Sealing. 2010. "Sex Trafficking: Inside the Business of Modern Slavery (Review)." Journal of World History 21 (2): 363-68. https://doi.org/10.1353/jwh.0.0120.

Coomaraswamy, Radhika. 2001. "Report of the Special Rapporteur on Violence against Women, Its Causes and Consequences, Ms. Radhika Coomaraswamy, in Accordance with Commission on Human Rights Resolution 2000/45: Mission to Bangladesh, Nepal and India on the Issue of Trafficking of Women and Girls."

E/CN.4/2001/73/Add.2.

http://hrlibrary.umn.edu/research/bagladesh/Appendix\%20J.pdf.

Ditmore, M. 1998. "Trafficking in Lives: How Ideology Shapes Policy." In Trafficking and Prostitution Reconsidered: New Perspectives on Migration, edited by Kamala Kempadoo.

Doezema, Jo. 1999. "Loose Women or Lost Women? The Re-Emergence of the Myth of White Slavery in Contemporary Discourses of Trafficking in Women." Gender Issues 18 (1): 23-50. https://doi.org/10.1007/s12147-999-0021-9.

Gallagher, Anne T. 2015. "Two Cheers for the Trafficking Protocol." Anti-Trafficking Review, no. 4: 14.

Hughes, Donna M., and Tatyana A. Denisova. 2001. "The Transnational Political Criminal Nexus of Trafficking in Women from Ukraine." Trends in Organized Crime 6 (3-4): 43-67. https://doi.org/10.1007/s12117-001-1005-7.

Human Trafficking. 2005. Crime, Drama, Mystery. http://www.imdb.com/title/tt0461872/.

ILO Convention Concerning Forced and Compulsory Labour. 1930. 39 UNTS 55, ILO No. 29.

ILO Convention Concerning Minimum Age for Admission to Employment. 1973. 1015 UNTS 290, ILO No. 138.

International Agreement for the Suppression of the White Slave Traffic. 1904.

International Convention for the Suppression of the White Slave Traffic. 1910. 3 LNTS 278.

Kara, Siddharth. 2010. Sex Trafficking: Inside the Business of Modern Slavery. Columbia University Press.

Moodysson, Lukas. 2003. Lilya 4-Ever. Crime, Drama. http://www.imdb.com/title/tt0300140/. 
Schloenhardt, Andreas, and Hannah Bowcock. 2015. "Sex Slaves and Shrewd Business Women: The Role of Victim Consent in Trafficking in Persons in Australia." Melb. UL Rev. 39: 592.

Skinner, E. Benjamin. 2009. A Crime So Monstrous: Face-to-Face with Modern-Day Slavery. Reprint edition. New York: Free Press.

Supplementary Convention on the Abolition of Slavery, the Slave Trade, and Institutions and Practices Similar to Slavery. 1957. Adopted by a Conference of Plenipotentiaries Convened by Economic and Social Council Resolution 608(XXI) of 30 April 1956 and Done at Geneva on 7 September 1956.

http://www.ohchr.org/EN/ProfessionalInterest/Pages/SupplementaryConventionAboli tionOfSlavery.aspx.

United Nations. 2006. Travaux Préparatoires of the Negotiations for the Elaboration of the United Nations Convention against Transnational Organised Crime and the Protocols Thereto. https://www.unodc.org/pdf/ctoccop_2006/04-60074_ebook-e.pdf.

United Nations Trafficking Protocol. 2000. Protocol to Prevent, Suppress and Punish Trafficking in Persons, Especially Women and Children, Supplementing the United Nations Convention against Transnational Organized Crime. https://treaties.un.org/Pages/ViewDetails.aspx?src=IND\&mtdsg_no=XVIII-12a\&chapter $=18 \&$ lang $=$ en.

UNODC. 2009a. UNODC Model Law against Trafficking in Persons. https://www.un.org/ruleoflaw/blog/document/unodc-model-law-against-traffickingin-persons/. 2009b. UNODC Model Law against Trafficking in Personsq.

Vijeyarasa, Ramona. 2010. "The Impossible Victim: Judicial Treatment of Trafficked Migrants and Their Unmet Expectations." Alternative Law Journal 35 (4): 217-22. http://classic.austlii.edu.au/au/journals/UTSLRS/2010/6.html. 2015. Sex, Slavery and the Trafficked Woman: Myths and Misconceptions about Trafficking and Its Victims. New edition. Farnham, Surrey, England ; Burlington, VT: Routledge.

Vijeyarasa, Ramona, and Jose Miguel Bello y Villarino. 2013. "Modern-Day Slavery - a Judicial Catchall for Trafficking, Slavery and Labour Exploitation: A Critique of Tang and Rantsev." Journal of International Law and International Relations 9: 38. http://heinonline.org/HOL/Page?handle=hein.journals/jilwirl9\&id=46\&div=\&collecti on $=$.

Vlieger, Antoinette. 2012. "Domestic Workers in Saudi Arabia and the Emirates: Trafficking Victims?" International Migration 50 (6): 180-94. https://doi.org/10.1111/j.14682435.2012.00785.x.

Vocks, Judith, and Jan Nijboer. 2000. The Promised Land: A Study of Trafficking in Women from Central and Eastern Europe to the Netherlands. Vol. 8. https://doi.org/10.1023/A:1008785214932.

Wijers, Marjan. 2015. "Purity, Victimhood and Agency: Fifteen Years of the UN Trafficking Protocol." Anti-Trafficking Review, no. 4: 56.

\section{NOTES}

\footnotetext{
${ }^{1}$ A more expansive short-list of relevant binding instruments would also take into account the ILO Conventions that specifically deal with forced labour, including ILO Convention No. 29 on Forced Labour; ILO Convention No. 105 on the Abolition of Forced Labour; and ILO Convention No. 182 on the Worst Forms of Child Labour.
} 
${ }^{2}$ I use hypotheticals not to be directive but rather to open up questions for inquiry. Each hypothetical is drawn
from the literature and also stories shared with me during my fieldwork in Ghana, Vietnam and Ukraine. They are intended to be archetypes rather than suggest that any individual hypothetical is a standalone true-life example.

${ }^{3}$ I recognise that Patience, the autonomous individual, is a falsehood. No decision can be deemed entirely autonomous. It is impossible to frame the decision of a female African migrant to seek work abroad as entirely autonomous, free of any gendered, cultural, racial or ethnic implications. However, for the purpose of this discussion, I frame Patience as an autonomous decision-maker.

${ }^{4}$ There are exceptions. See for example Ronit D. Leichtentritt 2005 on young male street workers in Israel or McCabe et al. 2011 on male street workers in Dublin.

5 Abolitionists call for an end to prostitution and trafficking alike. Pro-sex work feminists distinguish the voluntariness of sex work from trafficking. Throughout this article, I use the terms "prostitute" and "sex worker" interchangeably to remain true to the original passage and the preferred term of the author(s) being discussed or cited. My preferred terminology is "sex work" as a reflection that women voluntarily involved in sex work seek recognition of this work as a legitimate livelihood choice.

${ }^{6}$ The phrase itself is problematic, creating the image of a vulnerable woman or child targeted by perpetrating males.

${ }^{7}$ Balos' argument, while also focusing on women's choice and consent, is completely contrary to what I argue in this article. As an abolitionist, seeking an end to prostitution and trafficking, Balos argues that any attention to women's choices and consent 'obscures the systemic inequality that facilitates trafficking and the sexual exploitation of women' at 140 .

$\mathbf{8}$ This example is partially based on the discovery of a network of human traffickers who were accused of using the forced labour of around 450 Chinese men and women in 80 textile sweatshops in Catalonia, Spain. See CNN Freedom Project, "Unravelling the web of Spain's sweatshops", http://thecnnfreedomproject.blogs.cnn.com/2011/07/05/undercovers-crack-slave-labor-gang/, 5 July 2011. The example is also based on information provided to me during my own field research in Ukraine regarding a Ukrainian couple who left their child in Ukraine under the care of their parents after travelling to find work in Portugal. The husband ended up in exploitative labour in a factory, while the wife was forced to provide domestic services for the factory owner, who repeatedly raped her, before they were discovered, deported and received financial assistance from IOM in Ukraine.

${ }^{9}$ The Travaux Préparatoires indicate that 'debt' and 'debt bondage' were discussed but largely assumed to come within the meaning of the phrase 'forced labour'. See (United Nations 2006). 